\title{
Prediction of Vapour Liquid Equilibria for Binary Azeotropic Systems using Activity Coefficient Models
}

\author{
Sivaprakash .B, Manojkumar M.S
}

\begin{abstract}
Distillation operations are inevitable in chemical and petrochemical process industries. Design of distillation equipment requires knowledge of precise vapor-liquid equilibrium data. Due to the complexity and expenses incurred to obtain the VLE data experimentally for those systems for which the data are not available, solution thermodynamics and phase equilibria serve as an important tool in theoretical VLE prediction. In the current investigation five binary azeotropes namely Acetone-water, Acetone-methanol, Ethanol-water, Ethanol-benzene, and Methanol-water are taken for study. The theoretical prediction of VLE for these systems were computed using activity coefficient models namely NRTL, UNIQUAC, UNIFAC and modified form of Florry - Huggins equations (SRS and TCRS). The parameters for the five systems of four models viz. NRTL, UNIQUAC, SRS and TCRS were computed using Newton Raphson technique. UNIFAC model was adopted using Analytical solution of group contribution (ASOG) method. The performance of these models are tested using thermodynamic consistency test and validation from experimental VLE from literature. It was seen that the Acetone - Water system follows TCRS model, Acetone - Methanol and Ethanol - Water and Methanol - Water systems follow UNIFAC model, whereas SRS model suits for the Ethanol - Benzene system with highest accuracies.
\end{abstract}

Keywords: Vapour liquid Equilibrium, Azeotrope, Non ideal system, Activity Coefficient model, Thermodynamic consistency

\section{INTRODUCTION}

Separation of chemical in to the constituents is an art for millennia [1]. Chemical Engineers are more concerned with separations process. Separation methods include distillation, absorption, liquid-liquid extraction, leaching, drying and crystallization etc [2]. Distillation, which is the most widely, used separation technique in the chemical process industries [3] accounts for about $3 \%$ of the world energy consumption. Also it has substantial advantages over the other processes applied in order to separate a mixture, such extraction, crystallization, semi permeable membranes etc. Distillation process is based on the fact that the composition of the boiling liquid and that of the vapour over it differ. Thus, if the boiling temperature is low (e.g., air separation), it is necessary to use low temperature refrigerants and conduct the process at a higher pressure. If it is high (e.g., in separation of heavy oil fractions or metals), high temperature heat carries or fire preheating have to be used and the process is run under vacuum [4]. Because of the high energy demand of these processes the optimal design

Revised Manuscript Received on September 14, 2019.

Sivaprakash .B, Department of Chemical Engineering, Annamalai University, Annamalai Nagar, Tamilnadu, India

Manojkumar M.S, Department of Petrochemical Engineering, Mahendra Institute of Engineering and Technology, Nammakkal, Tamilnadu, India and operation of the distillation equipments are important from economic and also environmental points of view [5]. The presence of azeotropic mixture however complicates the design of ordinary distillation principles [6]. It is impossible to conduct the distillation process in the case of azeotropic composition.Azeotropes or close-boiling mixtures. The molecular interactions when two or more components are mixed may cause the mixture to form certain "inseparable" compositions where the vapor and liquid compositions at equilibrium are equal within a given pressure and temperature range. These specific mixture compositions are called azeotropes. The defining condition of an azeotropic mixture and the physical phenomena leads to nonideality. Nonideal mixtures exhibit positive $\left(\gamma_{\mathrm{i}}>1\right)$ or negative $\left(\gamma_{\mathrm{i}}<1\right)$ deviations from Raoult's law [. If these deviations become so large that the vapor pressure exhibits an extremal point at constant temperature, or, equivalently, an extremal point in the boiling temperature at constant pressure. Azeotropes play an important role in vapor-liquid equilibrium separation processes. For efficient design of distillation equipment or any other separation processes which are diffusional in nature requires quantitative understanding of vapour liquid equilibria. In Vapour liquid equilibrium phases are expressed through vapour phase fugacity coefficients and the liquid phase activity coefficients. At low or modest pressures fugacity coefficient can be estimated easily for very simple mixtures or ideal solutions, but for non-ideal mixtures, estimation of liquid phase activity coefficient is quite difficult [7]. In the present work five azeotropic systems namely acetone-methanol, chloroform-methanol, acetone-water, ethanol-benzene and methanol-water were taken for study. Experimental VLE of these systems were taken from literature. Applicability of five activity coefficient models to these systems were tested in the study viz. NRTL, UNIQUAC, UNIFAC and two forms of modified Flory - Huggins equations (SRS and TCRS). Also thermodynamic consistency test for these models was carried out by Redlich-Kister method.

\section{II.METHODOLOGY \&LOW PRESSURE VLE DATA REDUCTION}

There are different methods available for the regression of isothermal and isobaric VLE data. The gamma/phi $\left(\gamma-{ }_{\varphi}\right)$ formulation of VLE or more commonly known as the combined method was used in this work to regress the VLE data [8]. The combined method uses an equation of state to 
calculate the fugacity coefficients that describe the vapour phase non-idealities, while an activity coefficient model is used to calculate the activity coefficients that describe the liquid phase non-idealities. The gamma/phi method relies upon liquid phase activity coefficient models to represent VLE data, and give accurate result for non ideal solution which is given by

$$
\varphi_{\mathrm{i}} \mathrm{y}_{\mathrm{i}} \mathrm{P}=\gamma_{\mathrm{i}} \mathrm{x}_{\mathrm{i}} \mathrm{P}_{\mathrm{i}}^{\text {Sat }}
$$

$\mathrm{y}_{\mathrm{i}}$ is mole fraction in vapour phase; $\mathrm{x}_{\mathrm{i}}$ is mole fraction in liquid phase; $\mathrm{P}_{\mathrm{i}}^{\text {sat }}$ is vapour pressure and $\mathrm{P}$ is operating pressure; $\varphi_{i}$ is fugacity coefficient and $\gamma_{i}$ is activity coefficient.

\section{Fugacity Coefficient:}

At low to moderate pressure (0 to 10 atm), fugacity coefficient can be calculated by the following equations.

$$
\begin{aligned}
& \ln \varphi_{\mathrm{i}}=\left(\mathrm{B}^{0}+\omega \mathrm{B}^{1}\right) \mathrm{P}_{\mathrm{r}} / \mathrm{T}_{\mathrm{r}} \\
& \mathrm{f}_{\mathrm{i}}=\varphi_{\mathrm{i}} \mathrm{P} \\
& \mathrm{B}_{0}=0.083-0.422 / \mathrm{T}_{\mathrm{r}}^{1.6} \\
& \mathrm{~B}^{1}=0.139-0.172 / \mathrm{T}_{\mathrm{r}} 4.2
\end{aligned}
$$

$\phi_{\mathrm{i}}$ is fugacity coefficient; $\mathrm{B}^{0} \& \mathrm{~B}^{1}$ are virial coefficients; $\omega$ is accentric factor; $\mathrm{P}_{\mathrm{r}}$ is reduced pressure; $\mathrm{T}_{\mathrm{r}}$ is reduced temperature.

\section{Activity Coefficient Models:}

NRTL (Non-Random Two Liquid) Model

The non random two liquid (NRTL) equation proposed by Renon and Prausnitz, [9] is applicable to partially miscible as well as completely miscible systems. The equations for the activity coefficients are

$$
\gamma_{1}=x_{2}^{2}\left[\tau_{21}\left(\frac{G_{21}}{x_{1}+x_{2} G_{21}}\right)^{2}+\frac{\tau_{12} G_{12}}{\left(x_{2}+x_{1} G_{12}\right)^{2}}\right]
$$

$$
\gamma_{2}=x_{1}^{2}\left[\tau_{12}\left(\frac{G_{12}}{x_{2}+x_{1} G_{12}}\right)^{2}+\frac{\tau_{21} G_{21}}{\left(x_{1}+x_{2} G_{21}\right)^{2}}\right]
$$

where $G_{12}$ and $G_{21}$ energy interaction between the molecules.

UNIQUAC (UNIversal Quasi-Chemical) model

The UNIQUAC equation was developed by Anderson and Prausnitz [10] who incorporated the two-liquid model and the theory of local composition. The UNIQUAC equation consists of two parts a combinatorial part that takes into accounts the differences in sizes and shapes of the molecules and the residual part that is due to the intermolecular forces between the molecules. In the form of an equation, this is represented as

$$
\ln \gamma_{\mathrm{i}}^{\mathrm{C}}=\ln \frac{\phi_{\mathrm{i}}}{\mathrm{x}_{\mathrm{i}}}+\frac{z}{2} \mathrm{q}_{\mathrm{i}} \ln \frac{\theta_{\mathrm{i}}}{\phi_{\mathrm{i}}}+\mathrm{l}_{\mathrm{i}}-\frac{\phi_{i}}{\mathrm{x}_{\mathrm{i}}} \Sigma_{\mathrm{j}} \mathrm{x}_{\mathrm{j}} \mathrm{j}_{\mathrm{j}}
$$

$$
\begin{aligned}
& \ln \gamma_{i}^{R}=q_{i}\left[1-\ln \left(\Sigma_{j}{ }_{j} \tau_{j i}\right)-\Sigma j \frac{\theta_{j} \tau_{i j}}{\Sigma_{k} \theta_{k} \tau_{k j}}\right. \\
& l_{i}=\frac{z}{2}\left(r_{i}-q_{i}\right)-\left(r_{i}-1\right) \\
& r_{i}=\Sigma_{k} v_{k}^{i} R_{k} \\
& q_{i}=\Sigma_{k} v_{k}^{i} Q_{k}
\end{aligned}
$$

where $\phi_{i}=$ segment or volume fraction of the component $\theta \mathrm{i}=$ area fraction of the component

$r_{i}=$ volume parameter of the component

$\mathrm{q}_{\mathrm{i}}=$ surface area parameter of the component

UNIquac Functional group Activity Coefficient (UNIFAC) method

UNIFAC is based on UNIQUAC model, has a combinatorial term that depends on the volume and surface area of each molecule and a residual term that is the result of the energies of interaction between the molecules [11]. The combinatorial term is evaluated using equation (8) When using the UNIFAC model one first identifies the functional subgroups present in each molecule. Next the activity coefficient for each species is written as

$$
\begin{aligned}
& \ln \gamma_{\mathrm{i}}=\ln \gamma_{\mathrm{i}} \text { (combinato rial) }+\ln \gamma_{\mathrm{i}} \text { (residual) } \\
& \ln \gamma_{\mathrm{i}} \text { (residual) }=\Sigma_{\mathrm{k}} \mathrm{v}_{\mathrm{k}}^{\mathrm{i}}\left[\ln \Gamma_{\mathrm{k}}-\ln \Gamma_{\mathrm{k}}^{\mathrm{i}}\right] \\
& \ln \Gamma_{\mathrm{K}}=\mathrm{Q}_{\mathrm{k}}\left[1-\ln \left(\Sigma_{\mathrm{m}} \varphi_{\mathrm{m}} \Psi_{\mathrm{mk}}\right)-\Sigma_{\mathrm{m}} \frac{\varphi_{\mathrm{m}}-\psi_{\mathrm{km}}}{\Sigma_{\mathrm{n}} \varphi_{\mathrm{n}} \Psi_{\mathrm{nm}}}\right]
\end{aligned}
$$

$$
\Psi_{\mathrm{mn}}=\exp -\left[\frac{\mathrm{u}_{\mathrm{mn}}-\mathrm{u}_{\mathrm{nn}}}{\mathrm{RT}}\right]=\exp \frac{-\mathrm{a}_{\mathrm{mn}}}{\mathrm{T}}
$$

where $\Gamma_{\mathrm{k}}^{\mathrm{i}}$ is residual activity coefficient; $\mathrm{a}_{\mathrm{mn}}$ is interaction parameter; $\mathrm{u}_{\mathrm{mn}}$ is interaction energy between group $m$ and $n$.

Simplified Ruckenstein and Shulgin model (SRS)

The SRS equation for $\ln \gamma_{\mathrm{i}} \mathrm{S}$ are [12] given as

$$
\begin{gathered}
\ln \gamma_{1}=-\ln \left(\mathrm{x}_{1}+\mathrm{x}_{2} \mathrm{~L}_{12}\right)-\mathrm{x}_{2}\left[\mathrm{~A}_{12}-\mathrm{A}_{21}\right]-\left(\operatorname{lnL}_{12}+\operatorname{lnL}_{21}\right) \\
\left.\varphi_{1} \varphi_{2}+\mathrm{x}_{2} \varphi_{2} \frac{\partial \varphi_{1}}{\partial \mathrm{x}_{1}}+\mathrm{x}_{2} \varphi_{1} \frac{\partial \varphi_{2}}{\partial \mathrm{x}_{1}}\right] \\
\ln \gamma_{2}=-\ln \left(\mathrm{x}_{2}+\mathrm{x}_{1} \mathrm{~L}_{21}\right)-\mathrm{x}_{1}\left[\mathrm{~A}_{12}-\mathrm{A}_{21}\right]-\left(\operatorname{lnL}_{12}+\operatorname{lnL}_{21}\right) \\
{\left[\varphi_{1} \varphi_{2}+\mathrm{x}_{1} \varphi_{2} \frac{\partial \varphi_{1}}{\partial \mathrm{x}_{1}}+\mathrm{x}_{1} \varphi_{1} \frac{\partial \varphi_{2}}{\partial \mathrm{x}_{1}}\right]} \\
\mathrm{A}_{\mathrm{ij}}=\left[\frac{\mathrm{L}_{\mathrm{ij}}}{\mathrm{x}_{1}+\mathrm{x}_{2} \mathrm{~L}_{\mathrm{ij}}}\right]
\end{gathered}
$$




$$
\begin{aligned}
& \mathrm{L}_{\mathrm{ij}}=\frac{\mathrm{V}_{\mathrm{j}}}{\mathrm{V}_{\mathrm{i}}} \exp \left[-\frac{\lambda_{\mathrm{ij}-} \lambda_{\mathrm{ii}}}{\mathrm{RT}}\right] \\
& \varphi_{\mathrm{i}}=\frac{\mathrm{x}_{1}}{\mathrm{x}_{1}+\mathrm{x}_{2} \mathrm{~L}_{\mathrm{ji}}} \\
& \varphi_{\mathrm{j}}=\frac{\mathrm{x}_{2}}{\mathrm{x}_{2}+\mathrm{x}_{1} \mathrm{~L}_{\mathrm{ji}}}
\end{aligned}
$$

where $\mathrm{x}_{1}$ and $\mathrm{x}_{2}$ are mole fraction in liquid phase. $\mathrm{A}_{12}$ and $A_{21}$ are two adjustable parameters related to pure component molar volume and characteristic energy difference. $\varphi_{1}$ and $\varphi_{2}$ are segment fraction of the components and $\chi$ is an energy interaction between molecules of components.

Theoretically Consistent Ruckenstein and Shulgin model (TCRS)

Like NRTL equation the new equation (TCRS) is also three parameter models. Their expression for $\ln \gamma_{\mathrm{i}}$ 's are [12]

\section{Mathematical Computation}

The theoretical estimation of VLE using the five activity coefficient models, NRTL, UNIQUAC, UNIFAC, SRS and TCRS was accomplished using Newton Raphson technique with computer programming in Java software of 1.6 version. The output of the programming yielded the parameters of the models along with the theoretical values of the VLE. The relative error percentages between the experimental and model predicted vapour phase mole fractions are calculated using the equation

$$
\mathrm{REy}_{1}=\frac{\mid \mathrm{y}_{1} \text { Experiment al }-\mathrm{y}_{1} \text { Calculated } \mid}{\mathrm{y}_{1} \text { Experiment al }} \times 100
$$

Thermodynamic Consistency test :

Of all the thermodynamic consistency tests the integral test proposed by Redlich - Kister given below is employed.

$$
\begin{aligned}
& \begin{array}{c}
\ln \gamma_{1}=-\ln \left(x_{1}+x_{2} L_{12} \exp \left(x_{1} \delta_{12}\right)\right)+x_{2}\left[A_{i j}-A_{j}\right. \\
\left.\varphi_{1} \varphi_{2}+x_{2} \varphi_{2} \frac{\partial \varphi_{1}}{\partial x_{1}}+x_{2} \varphi \frac{\partial \varphi_{2}}{\partial x_{1}}\right]-2 x_{2} \varphi_{1} \varphi_{2} \delta_{12}
\end{array}
\end{aligned}
$$

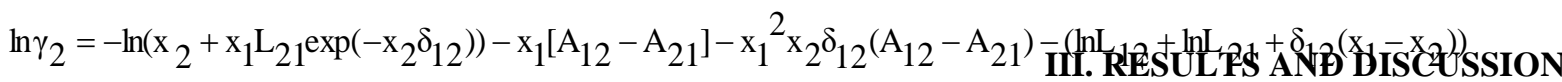$$
\left[\varphi_{1} \varphi_{2}-x_{1} \varphi_{2} \frac{\partial \varphi_{1}}{\partial x_{1}}+x_{1} \varphi_{1}-x_{1} \varphi_{1} \frac{\partial \varphi_{2}}{\partial x_{1}}\right]+2 x_{1} \varphi_{1} \varphi_{2} \delta_{12}
$$

$$
\text { Lij }=\frac{V_{j}}{V_{i}} \exp \left[\frac{\lambda_{i j}-\lambda_{i i}}{R T}\right]
$$$$
\delta_{12}=\left[\frac{\lambda_{12}-\lambda_{21}}{R T}\right]
$$

The vapour phase ideality was characterized by fugacity coefficient calculation using equations (2-5). From the calculations, the fugacity coefficient was found to be closer to unity. Hence it is reasonable to consider that the vapour phase for all the five systems taken in the present study as ideal. The activity coefficient $\left(\gamma_{1}\right)$ calculated from the experimental VLE using Equation (1) for the five azeotropic systems is also incorporated in tables 1-5. Since the numerical values of activity coefficient $\left(\gamma_{1}\right)$ are greater than unity for all the systems the liquid phase feature strong non ideality. This is due to the fact that the liquid phase molecules are much closely spaced than in vapor phase due to which attraction / repulsion among the molecules are high. Also all the five azeotropic systems show positive

\begin{tabular}{|c|c|c|c|c|c|c|c|c|}
\hline \multirow{2}{*}{ System } & \multicolumn{2}{|c|}{ NRTL J/mol K } & \multicolumn{2}{|c|}{ UNIQUAC J/mol K } & \multicolumn{2}{|c|}{ SRS J/mol K } & \multicolumn{2}{|c|}{ TCRS J/mol K } \\
\hline & $\lambda_{12}-\lambda_{11}$ & $\lambda_{21}-\lambda_{22}$ & $\mathbf{u}_{12}-\mathbf{u}_{22}$ & $\mathbf{u}_{21}-\mathbf{u}_{11}$ & $\lambda_{12}-\lambda_{11}$ & $\lambda_{21}-\lambda_{22}$ & $\lambda_{12}-\lambda_{11}$ & $\lambda_{21}-\lambda_{22}$ \\
\hline $\begin{array}{l}\text { Acetone- } \\
\text { water }\end{array}$ & 2160.1319 & 18602.345 & $\begin{array}{l}- \\
580.1319\end{array}$ & 1112.3450 & 3066.913 & 29.5959 & $\begin{array}{l}5326.913 \\
0\end{array}$ & - 2230.4040 \\
\hline $\begin{array}{l}\text { Acetone- } \\
\text { methanol }\end{array}$ & - 17460.218 & $\begin{array}{l}- \\
51385.655\end{array}$ & 4769.778 & 19434.015 & 1646.530 & -1633.5299 & 8046.530 & - 8033.5299 \\
\hline
\end{tabular}
deviation from ideality (minimum boiling azeotropes). This is because the dissimilar molecular structures of five azeotropic systems exert repulsive forces other than attractive forces. The repulsive forces results in higher concentration of molecules in vapour phase than in the liquid phase with higher activity coefficient $(\gamma)$

$$
\varphi_{j}=\frac{x_{2}}{x_{2}+x_{1} L_{j i} \exp \left[-x_{2} \delta_{12}\right]}
$$

Table 1.Estimated NRTL, UNIQUAC, SRC and TCRS parameters of five azeotropic systems 
Ethanol-

water

Ethanol-

benzene

Methanol water
- $1835.131 \quad 12920.345$

860.1319

1392.345

1232.8499

3400.00

1852.849

2780.00

$$
-1920.13199922 .3450
$$

320.1319

852.3450

$167.1500 \quad 4800.00$

132.8499

4500.00

$699.8679 \quad 1542.3499$

12399.86
The experimental and correlated $x-y$ diagrams of five azeotropic systems using the five models are given in Figures 1-5.

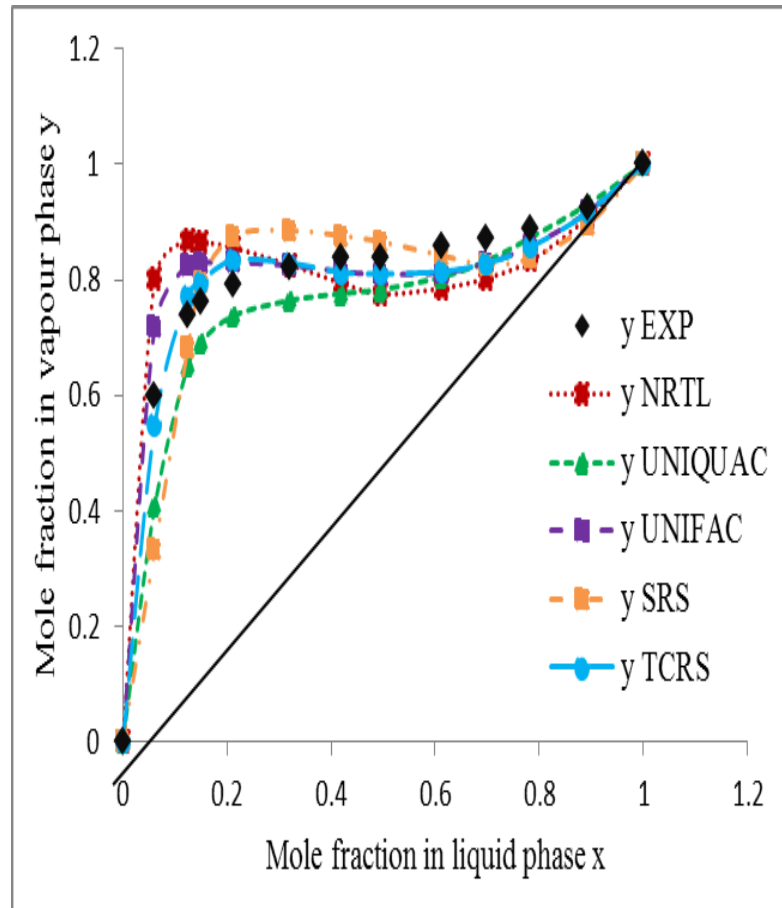

Figure 1. Experimental and Correlated xy Diagram of Acetone-water System at $101.325 \mathrm{kPa}$.

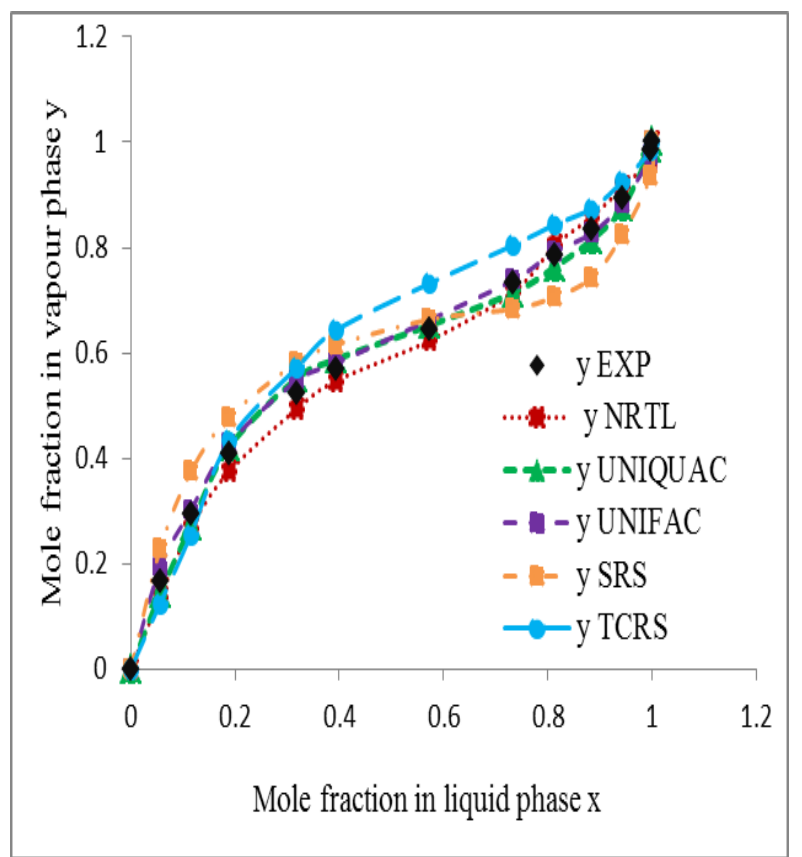

Figure 2. Experimental and Correlated xy Diagram of Acetone-methanol System at $101.325 \mathrm{kPa}$.

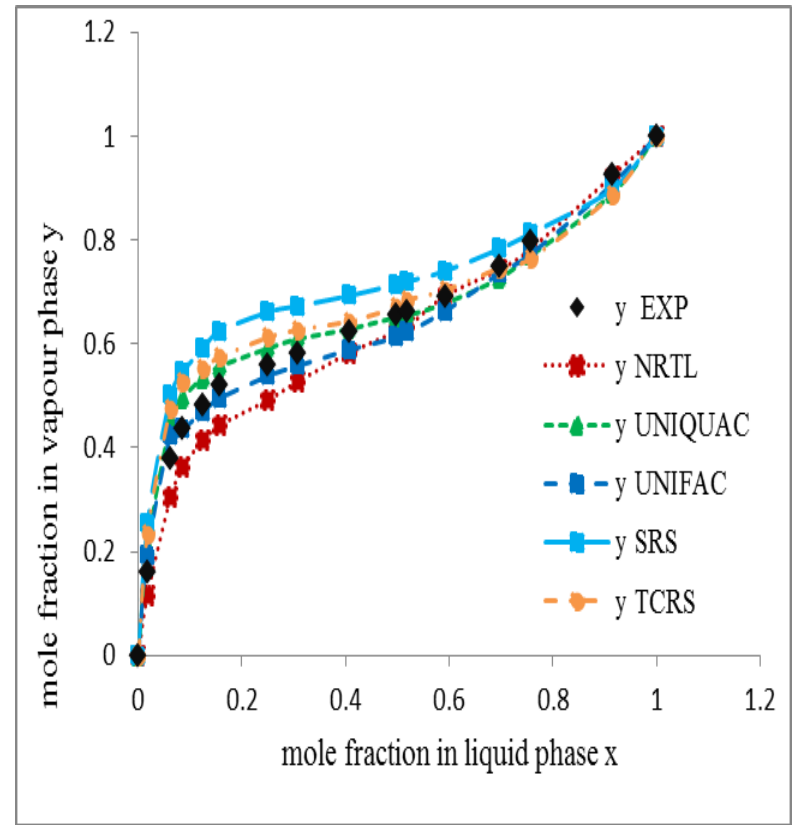

Figure 3. Experimental and Correlated xy Diagram of Ethanol-water System at $101.325 \mathrm{kPa}$.

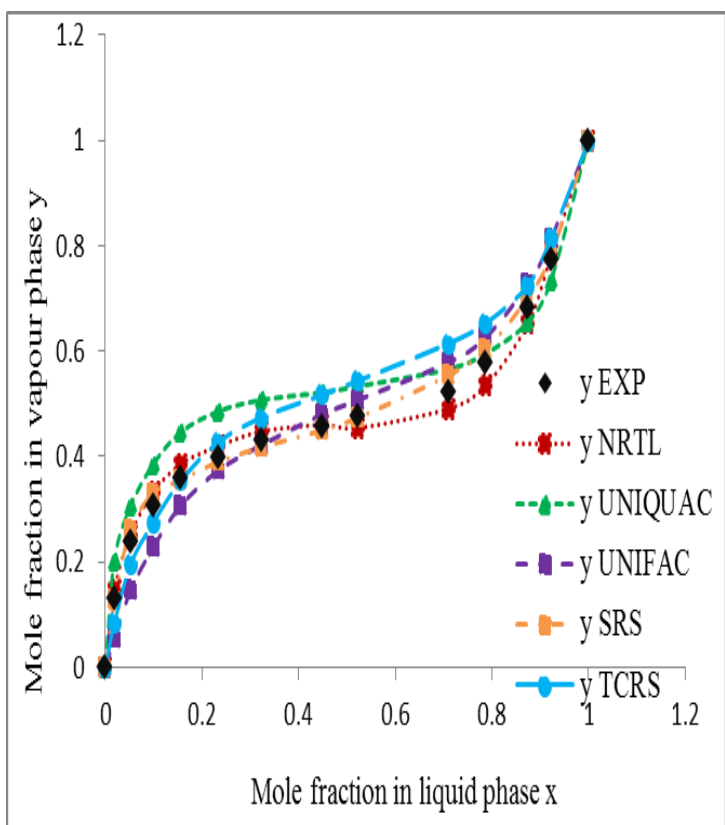

Figure 4. Experimental and Correlated xy Diagram of Ethanol-benzene System at $101.325 \mathrm{kPa}$.

Published By: 


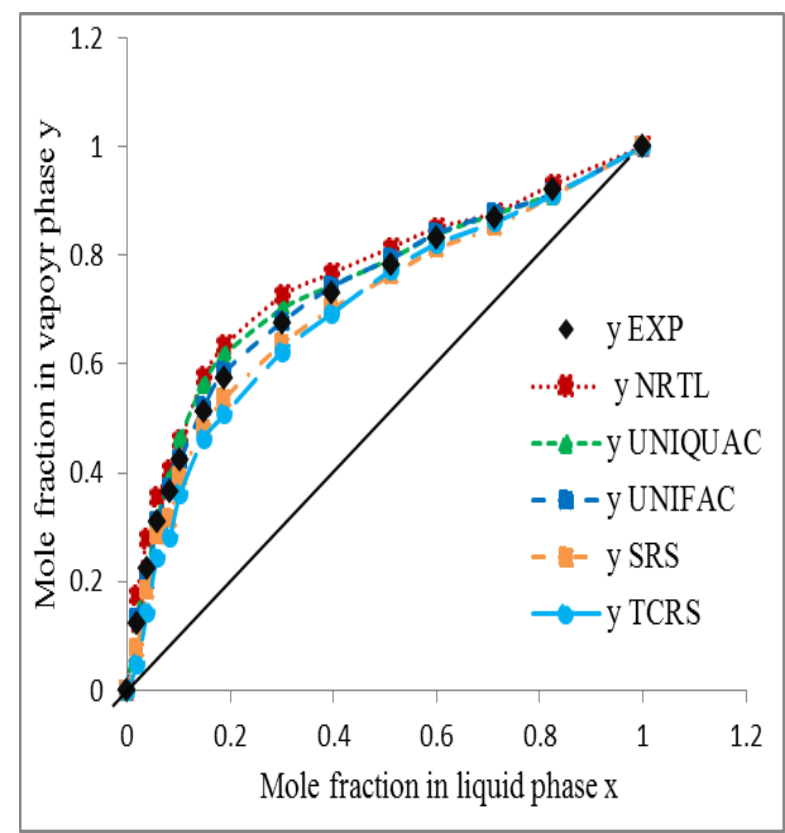

Figure 5. Experimental and Correlated xy Diagram of Methanol-water System at $101.325 \mathrm{kPa}$.
The overall error percentages of the VLE for acetonewater system using five activity coefficient models NRTL, UNIQUAC, UNIFAC, SRS and TCRS are 7.9438, 8.4590, $6.0952,8.9785$, and 4.0380 respectively. It is observed that TCRS model have lesser error percentages than the other four models. Acetone-methanol system shows significant validity for the UNIFAC and UNIQUAC models with the least error percentage of 3.3167 and 4.1357 whereas the other models have more than $5 \%$. Error occurred in UNIFAC model $(5.6071 \%)$ provide good representation of VLE for ethanol-water system when compared to other models. The SRS and NRTL model gave better results for the ethanol-benzene system yielding an error percentage of 3.5758 and 5.6974. Of all the five models chosen, the UNIFAC and UNIQUAC models gives better result for methanol-water system with least error percentage of 2.3301 and 4.5305 .

Related outcome were observed with the Redlich-Kister method of thermodynamics consistency test (Eq. 31) and reported in Table 2.

Table 2 Thermodynamic Consistency test of five azeotropes system using Redlich - Kister method

\begin{tabular}{llllll}
\hline System & \multicolumn{2}{l}{ Area Under the Curve } & & \\
\cline { 2 - 6 } & NRTL & UNIQUAC & UNIFAC & SRS & TCRS \\
\hline Acetone-water & 0.0791 & 0.09075 & 0.01625 & 0.4445 & $\mathbf{0 . 0 0 3 7 5}$ \\
$\begin{array}{l}\text { Acetone- } \\
\text { methanol }\end{array}$ & 0.1789 & 0.08512 & $\mathbf{0 . 0 3 6 2 1}$ & 0.2172 & 0.2005 \\
$\begin{array}{l}\text { Ethanol-water } \\
\text { Ethanol- }\end{array}$ & $\mathbf{0 . 0 1 5 8}$ & 0.0221 & 0.0201 & 0.1173 & 0.1067 \\
$\begin{array}{l}\text { benzene } \\
\text { Methanol-water }\end{array}$ & 0.0165 & 0.4714 & 0.4041 & $\mathbf{0 . 0 0 5 4}$ & 0.3823 \\
\hline
\end{tabular}

It can be seen that value of TCRS model close to zero for acetone-water system. In a similar approach the acetonemethanol system shows good thermodynamic consistency for UNIFAC and UNIQUAC activity coefficient models whereas the ethanol-water own good concurrence with UNIFAC model. For ethanol-water system SRS and NRTL model gives better result of VLE consistency. Correspondingly UNIFAC and UNIQUAC models show appreciable thermodynamic consistency for methanol-water system. The order of fitness for each system is furnished in Table 3.

Table 3 Order of fitness for the azeotropes

\begin{tabular}{|c|c|c|}
\hline $\begin{array}{l}\text { S. } \\
\text { No. }\end{array}$ & $\begin{array}{l}\text { Azeotropic } \\
\text { System }\end{array}$ & Order of fit \\
\hline 1 & Acetone - Water & $\begin{array}{l}\text { TCRS }>\text { UNIFAC }>\text { NRTL }> \\
\text { UNIQUAC }>\text { SRS }\end{array}$ \\
\hline 2 & $\begin{array}{l}\text { Acetone } \\
\text { Methanol }\end{array}$ & $\begin{array}{l}\text { UNIFAC > UNIQUAC > } \\
\text { NTRL }>\text { TCRS }>\text { SRS }\end{array}$ \\
\hline 3 & Ethanol - Water & $\begin{array}{l}\text { UNIFAC > UNIQUAC } \\
>\text { TCRS > NRTL }>\text { SRS }\end{array}$ \\
\hline 4 & $\begin{array}{l}\text { Ethanol } \\
\text { Benzene }\end{array}$ & $\begin{array}{l}\mathrm{SRS}>\mathrm{NRTL}>\mathrm{TCRS}> \\
\text { UNIFAC }>\text { UNIQUAC }\end{array}$ \\
\hline 5 & $\begin{array}{l}\text { Methanol } \\
\text { Water }\end{array}$ & $\begin{array}{l}\text { UNIFAC > UNIQUAC > } \\
\text { SRS }>\text { NRTL }>\text { TCRS }\end{array}$ \\
\hline
\end{tabular}

\section{CONCLUSION}

In case of VLE prediction of azeotropes, NRTL, UNIQUAC UNIFAC, SRS and TCRS models were tested for the systems namely Acetone-water, Acetone-methanol, Ethanol-water, Ethanol-benzene, and Methanol-water. The experimental VLE findings show that all the five systems show minimum boiling azeotropes (positive deviation from ideality). Major finding of the present work is the estimation of NRTL, UNIQUAC, SRS and TCRS parameters for the five systems. These parameters can be utilized for VLE calculation at any temperature and pressure conditions.

\section{REFERENCES}

1. Seader, J. D., J. Henley, 2006. Separation process Principles, John Wiley and Sons Publication, New Jersey.

2. Geankoplis, C.J., 2003. Transport Process and Separation Process, Prentice Hall Publication, New Jersey.

3. Vivekjulka, MadhuraChiplunkar, L. O. Young, 2009. Selection Entariner for Azeotropic Distillation, Chemical Engineering Progress, 47-53. 
4. MohamadAzamudin, I., 2010. Effects of Temperature On Vapor Liquid Equilibrium OfMtbe-Methanol Mixtures, Bachelor thesis, University Malaysia Pahang.

5. Laszlo, H., 2013. Improvement of Batch Distillation Separation of Azeotropic Mixtures, Phd thesis, Budapest University of Technology and Economics.

6. Gadekar, S. V., R. V. Naik, J. D. Bapat, 2004. Acetic Acid-Water-Toluene System Batch Distillation Parametersfor Heterogeneous Azeotropic systems, Chemical Engineering World, 44.

7. Managobinda, B., 2010. VLE modeling Using Unifac Group Contribution Method and its application in Distillation Column Design and Steady State Simulation, Dissertation for Bachelor thesis, National Institute of Technology, Rourkela.

8. Negema, P. T., 2010. Separation process for high purity ethanol production, Dissertation for the M.S. Degree, Durban University of Technology.

9. Renon, H., J.M. Prausnitz, 1968. Local Compositions in Thermodynamic Excess Functions for Liquid Mixtures, Journal of American Institute of Chemical Engineers, 14: 135-144.

10. Anderson, T.F., J.M Prausnitz, 1978. Application of the UNIQUAC equation to calculation of multicomponent phase equilibria, Industrial and Engineering Chemistry Process Design and Development, 17 (4): 561-567.

11. Fredenslund, A., J. Gmehling, M.L. Michelson, P. Rasmussen, 1977. Computerized Design of Multicomponent Distillation Columns using the UNIFAC Group Contribution Method, Industrial and Engineering Chemistry Process Design and Development 16 (4): 450-462.

12. Sabarathinam, P.L., B. Sivaprakash, 2002. Theoretically consistent modified Local composition and Floryhuggins equations in VLE data prediction, M. E.Thesis, Annamalai University.

\section{AUTHOR PROFILE}

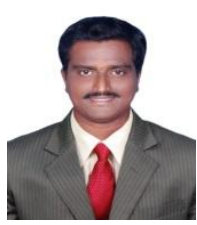

Dr. B. Sivaprakashis working as an Associate Professor in the Department of Chemical Engineering, Annamalai University. He has a teaching experience of 17 years and research experience of 18 years. His fields of interest are Solution Thermodynamics and Bioprocess Modeling. He has guided one doctoral student and 15 post graduate students and has published 23 research papers in journals. He has attended 25 National and International conferences and visited Thailand, Singapore and Malaysia on academic background. He served as the Coordinator of the Students' Chapter of the Indian Institute of Chemical Engineers - Annamalai Regional Centre (July 2006 to June 2017) and received the Pidelite Best Student Chapter award in 2010. Presently he is the Faculty Advisor of the Chemical Engineering Students' Chapter of The Institute of Engineers (India) - Annamalai University Centre. In 2019 he bagged two Tamilnadu State awards Viz. Best Faculty Advisor award and the Best Division award. He is also serving as the NSS and RRC Programme officer in the Department of Chemical Engineering. He has organized one ISTE STTP sponsored by the CSIR, Hyderabad, two National Conferences funded by the UGC, DST - SERB, New Delhi and TNSCST, Tamilnadu, two seminars and one industrial workshop funded by UGC. He is a placement trainer and serving as placement coordinator in the Department of Chemical Engineering for 13 years.

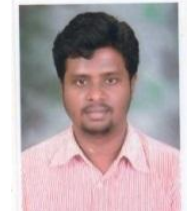

Dr. M. S. Manojkumar is Working as an Assistant professor in Department of Petrochemical Engineering, MIET Namakkal. $\mathrm{He}$ has teaching experience of five years and six years of research experience. His fields of interest are Chemical engineering Thermodynamics and Distillation .He has published six research journals and he has attended seven national and international conferences. 